\title{
A better place? Factors in community assessment for parents of children with Down syndrome
}

\author{
Amelia N. Gibson
}

\begin{abstract}
Information seeking often occurs in groups and communities, and these communities differ in ways that impact their usefulness to their members. This study uses grounded theory and information horizons mapping to explore information seeking and sharing in two place-based communities in Florida, addressing factors associated with participants' evaluations of their local communities of support. These factors provide insight into parents' expectations of their information worlds and expectations related to information behaviors of actors within their local information environments. The study finds similar stakeholder groups similar expressions of the belief that some communities were "better" than others for raising children with Down syndrome in both areas, but varying evaluations of their own communities based on personal experiences. Participants agreed on the following factors as important indicators of a strong local community of support: existence and activities of local parent networks and organizations, access to quality education and health care, full inclusion in regular education when desired, social inclusion of their children into the community at large, and employability for adults with Down syndrome.
\end{abstract}

Published version can be found in Proceedings of the American Society for Information Science and Technology:

Gibson, A. N. (2014). A better place? Factors in community assessment for parents of children with Down syndrome. Proceedings of the American Society for Information Science and Technology, 51(1), 1-10. doi:10.1002/meet.2014.14505101063 


\section{Background and purpose}

Individuals with Down syndrome in the United States are living longer lives, and encountering new information environments. Widespread inclusion has become the norm in most places in the United States, but implementation of full inclusion (and provision of the support needed to maximize the abilities of individuals with Down syndrome to live independently in their local communities) has proved difficult in other places. Attitudes and policies about including and supporting people with Down syndrome vary from place to place despite federally established guidelines. In many places, parents of children with Down syndrome form support and advocacy groups to seek and share information and resources. Although these groups are sometimes loosely affiliated with national organizations, they are locally organized, and reflect the needs of local parents in their local communities. They sometimes partner with other individuals and organizations in local communities to provide the support parents feel they need to optimize health and learning outcomes for their children.

This paper examines the factors participants use to informally assess the strength of their local communities of support to better understand the attributes that make the communities useful to their members; examines these factors as they relate to information access and behavior; and provides a thick description of the contexts within which participants make assessments. Because researchers use the concept of "community" in different contexts (Veinot \& Williams, 2012), it is necessary to establish limitations on the definition of community, and to refine the definition based on study data. The paper reassess the initial definition (described below) as applied to the study participants through comparison with interview data. It also includes discussion about the participants' definitions of "local community."

\section{About Down Syndrome}

Down syndrome is a genetic condition in which an individual is born with an extra copy of the 21st chromosome. It is one of the most commonly occurring genetic conditions in the United States (Parker, et. al., 2010; Mai et al., 2013) with a prevalence of 1 in every 700 births. The prevalence of Down syndrome at birth increased by 31.1\% between 1979 and 2003 in the United States (Shin et al., 2009), and the survival probability for children with Down syndrome has increased between 1983 and 2003 (Kucik, Shin, Siffel, Marengo, \& Correa, 2013). The National Institutes of Health has determined that new health-related issues faced by individuals with Down syndrome (based on this extended lifespan) necessitate more research and new programs (Eunice Kennedy Shriver National Institute of Child Health and Human Development, 2007).

The influence of this chromosomal difference on individual health varies among people with Down syndrome, who have increased risk for developmental delay, intellectual disability, heart and pulmonary diseases, Alzheimer's disease, and other conditions (McCabe \& McCabe, 2013). Children with Down syndrome typically have mild to moderate cognitive delays and many have speech and various motor delays. A combination of medical and therapeutic advances, and community living have improved health outcomes, and increased the life span and inclusion of this population. The life expectancy in the United States for individuals with Down syndrome in the United States increased from 25 years in 1983 (Yang, 
Rasmussen, \& Friedman, 2002), to approximately 60 years in 2006 (Bittles, Bower, Hussain, \& Glasson, 2007).

\section{Changing Information Needs}

Improvements in services and treatments present people with Down syndrome and their families with new situations and new information needs. Many of these information needs have not been previously studied in this population. Research about parents of children with Down syndrome has focused largely on emotional needs, and stress levels of parents (Atkinson et al., 1995; Damrosch \& Perry, 1989; Rodrigue, Morgan, \& Geffken, 1992), rather than information needs of children and adults living in communities, or the needs of the family members who sometimes act as caretakers. Because normalization of community residence as a practice for individuals with Down syndrome is a fairly recent occurrence, community- oriented research about the information needs of individuals with Down syndrome and their families is also undeveloped.

The ability of local communities to meet the information and service needs of individuals with Down syndrome and their families can impact service provision, by extension, development and health. Local funding, knowledge about the needs of people with Down syndrome, and the ability and willingness of local agency administrators to work to improve information and service access in ways that meet the needs of the local community all potentially impact information access and literacy of parents. Additional barriers, such as cultural differences between information and service providers and parents could all negatively impact children's access to services, and parents' access to information. Other studies have explored the information seeking behaviors of individuals and families of individuals with Autism and other developmental disabilities (Jegatheesan, Fowler \& Miller, 2010; Mackintosh, Myers, \& GoinKochel, 2005; Pain, 1999; Ammari, Morris, \& Schoenbeck, 2014), but this study focuses Down syndrome in particular, and on community structure as a determinant in health-related information behavior.

A rich body of research has connected health to place and/or community over the last decade (Gastaldo, Andrews, \& Khanlou, 2004; Rais \& Viana, 2010; Grekousis \& Photis, 2014), but has not largely focused on information behavior. LIS researchers have worked to improve information access for individuals with disabilities in libraries (Hill, 2013), and on the Internet (Dobransky \& Hargittai, 2006; Huang, 2003; Jaeger, 2006), but have done less to explore the role of the place and community in health information access and behavior. More recent multi-method research has begun to explore the role of community in sharing and seeking health related information with regard to HIVIAIDS, exploring what community related variables influence the HIVIAIDS information-seeking behaviors of gay men (V einot, Meadowbrooke, Loveluck, Hickok, \& Bauermeister, 2013), comparison of rural and urban information exchange with regards to HIVIAIDS (Veinot \& Harris, 2011), and individuals with chronic disease in Flint, Michigan (Kaziunas, Ackerman, \& Veinot, 2013). Veinot et. al (2013) provides a more complete synopsis of community related research in information behavior research.

\section{Defining Community}


For the purposes of this study, a community is defined as a group of people who, to some degree, share culture, identity, experience, and place (Day, 2006; Herb \& Kaplan, 1999; Lewis, 1983). Culture refers to the combined set of social norms, language, and information values (Jaeger \& Burnett, 2010) that are shared by a group, all of which mark its members as distinct from those of other groups (Mitchell, 2000). Identity is defined as sense of belonging to a group, regardless of official membership or naming conventions. Place refers to geographic location, but is also strongly connected with the actors (people, groups, and institutions) that occupy that location, their experiences (behaviors and interactions), and social institutions, all of which create "sense of place" (Agnew, 1987; Tuan, 1975). This study examines this sense of place and, to some degree, participants' affective sense of the strength of community. It also examines how the structure of this community affects information access, seeking, and sharing.

This paper derives its place-based definition of community from critical border studies and human geography literature, which view borders as contested and constantly changing based on cultural and sociological factors influencing the resident population (Paasi, 2012; Simmel, 1997). This is in contrast to the view of place and communities as defined by administrative boundaries imposed by governments. Coopting this critical approach to defining "local," "place," and "community" is appropriate for the study of parent information behavior, as this study explores issues related to human information behavior in addition to patterns and placement of "artifacts on the ground" (Agnew, 2008). Study participants are asked to evaluate their local communities. Allowing them to also define the borders of those communities provides insight into parent information worlds and information networks without censuring portions of networks that violate arbitrary geographical boundaries.

\section{Phenomena of Interest}

Improved understanding of individuals' expectations and information needs enables community stakeholders to plan effective services and communication, and to design information systems to meet those needs. In addition to addressing substantive issues related to the study participants, this paper outlines a qualitative approach toward exploring the expectations of specific place-based communities. The process of mapping the participants' information horizons establishes a list of information and service providers participants consider a part of their community of support, whether or not they personally engage in active information exchange with these actors. The use of open coding and grounded theory analysis, allows concepts to emerge from the data, rather than imposing externally determined categories or preset answers. This paper focuses specifically on social factors present in place-based communities that influence information access, seeking or sharing among study participants, and factors participants consider when assessing their local place-based communities with regards to information access and sharing.

\section{Materials and methods}

\section{Participants}

Twenty-eight English-speaking parents of children with Down syndrome (13 in Leon County, and 15 in Palm Beach County, Florida) participated in this study. A combination of purposive and snowball sampling was used to recruit participants. Local Down syndrome advocacy 
organizations in the study areas sent introductions and calls for participation to their members via email and Facebook. Volunteers were asked to contact the researcher, and to forward the call to other potential participants. Participants were asked to respond directly to the researcher to set up interview appointments.

\section{Methods}

This multi-method study combines public participation mapping, information horizons mapping (Sonnenwald \& Wildemuth, 2001) and grounded theory interview analysis (Strauss \& Corbin, 1998). This study was part of a larger study exploring the Information Worlds (Jaeger \& Burnett, 2010) of parents of individuals with Down syndrome. This paper focuses on information horizons mapping and interview data as they relate specifically to participants' assessments of their local communities and the effect of community on information sharing, seeking and access.

Participants were asked to describe their experiences seeking information on behalf of their children with Down syndrome in semi-structured interviews, and to illustrate their "communities of support" (people, places and organizations that provided information and/or services for them or their children related to Down syndrome or related needs). During interviews, participants were asked about situations in which they sought information but did not receive sufficient information, situations in which they received sufficient information, and situations in which they received too much information. They were asked to describe resources that they had used within the previous year, where they had heard about those resources, whether they thought their local community of support was strong, and why or why not. Finally, they were asked for advice they might want to share with a parent of a newborn with Down syndrome. The goal was to elicit as much information as possible about their information seeking experiences, and about the local sources used to find this information. Unlike Sonnenwald \& Wildemuth's (2001) study, they were not asked to explicitly number the order in which they sought information, but they were asked to identify the sources of information they had sought or found within the past year. Participants were also asked to draw information networks that illustrated their communities of support, with themselves and their families at the center. The list of individuals and groups developed form these networks were open coded, and categories of actors emerging from the data were used to develop a diagram of community stakeholders. Members of the community are referred to in this paper as actors in the case of specific individuals and organizations (Jaeger \& Burnett, 2010) and stakeholder groups when they represent larger categories of actors.

\section{Limitations}

This study does not attempt to make generalizable claims about the nature of community or the more substantive issues identified in the findings. The goal is to create a starting point for further research by identifying an initial group of substantive issues for exploration. The study also focuses on thick descriptions of information behaviors.

Because grounded theory analysis is used to parse interview data, and the study relies on interpretation of participants' personal experiences, the researcher makes no claim to objectivity (Kaplan, 2009). Instead, I attempt to avoid unduly imposing personal opinion upon 
the data, and ensuring trustworthiness is through constant comparison, member checks, memoing, and intracoder reliability (Strauss \& Corbin, 1998). Intracoder reliability was ensured through iterative coding, and allowing 1-month intervals between coding and recoding each interview.

Local parent organizations assisted in recruiting participants by emailing an introduction to listserv and Facebook group members. This may have introduced a bias favoring the importance of the parent organization, as some participants would have already been active in the participant organization. Additionally, because the snowball sampling method asks individuals to refer others, it is possible that participants were more likely to be active members in the parent organization (who have a predisposition toward valuing the role of the organization), or to know someone who did. This bias would be difficult to verify without consulting a list of the population, or compromising the confidentiality of study participants.

The use of a snowball sample allowed for the discovery of potential participants among what might otherwise be a hard to reach community. It was not possible to build a sampling frame from which to draw a random sample because there were no available lists of all parents of individuals with Down syndrome in the study areas (membership in the two parent organizations were open to any interested party, and not limited to individual with Down syndrome and their families). Any information about children born with Down syndrome available to local medical facilities or government agencies is protected by federal law. The snowball sampling process also served as a form of verification and recommendation among parents in the study communities. Some participants only recommended that others participate after completing the interview process themselves. While the inclusion of the snowball sampling method limits the application of the findings in terms of generalizability, it allowed for participants to exercise some self-determination in establishing the boundaries of the local community, as parents were asked to help recruit other "local" parents.

\section{Findings and discussion}

\section{Participant Interpretations of "Community of Support"}

The interview question relating to community assessment asked participants whether they felt the local community of support is strong or not, and why or why not. Community of support had been previously defined as "any local person, place, individual or organization that supports you and your family as you raise your child with Down syndrome." Participant responses justifying their assessments provided some insight into the participants' concept of community of support. They fell into the following categories:

\section{Evaluation of information and services available via local organizations and}

individuals -participants discussed the availability and perceived quality of services available to them and their children as members of the local community. These included evaluations of medical facilities and professionals, the school system, transportation, and the parent organization (as a formally organized entity).

Description of distance to and from information and services - participants discussed the physical layout of the local community, citing the distance to medical services, therapy, and events held by the parent organization as positive or negative indicators of the strength 
of the local community. These assessments indicate that participants' concept of community included the physical space and places. Evaluation of this facet of the community related to proximity and physical access to places that constitute the community of support.

Affective experiences - participants' assessments of their local communities varied with emotional experiences with members of the community. Although these assessments were mainly focused on the Community at Large, extremely negative emotional experiences were often attributed to the community at large, even when they resulted from interactions with professionals. Here I include the perception of social acceptance of children with Down syndrome individually, and acceptance of the entire group of parents of children with Down syndrome in the local community (indicated by larger programs, such as the Buddy walk).

\section{Community Stakeholders}

Categories of community stakeholders emerged through open coding of the data. The following eight groups represent an aggregation of stakeholders present in the two communities: other parents of children with Down syndrome, Down-syndrome-related organizations (DSO), extended families, medical personnel, therapists, educators, government/assistance agencies, local schools and local community at large. Figure 1 represents the community of support as described by the participants.

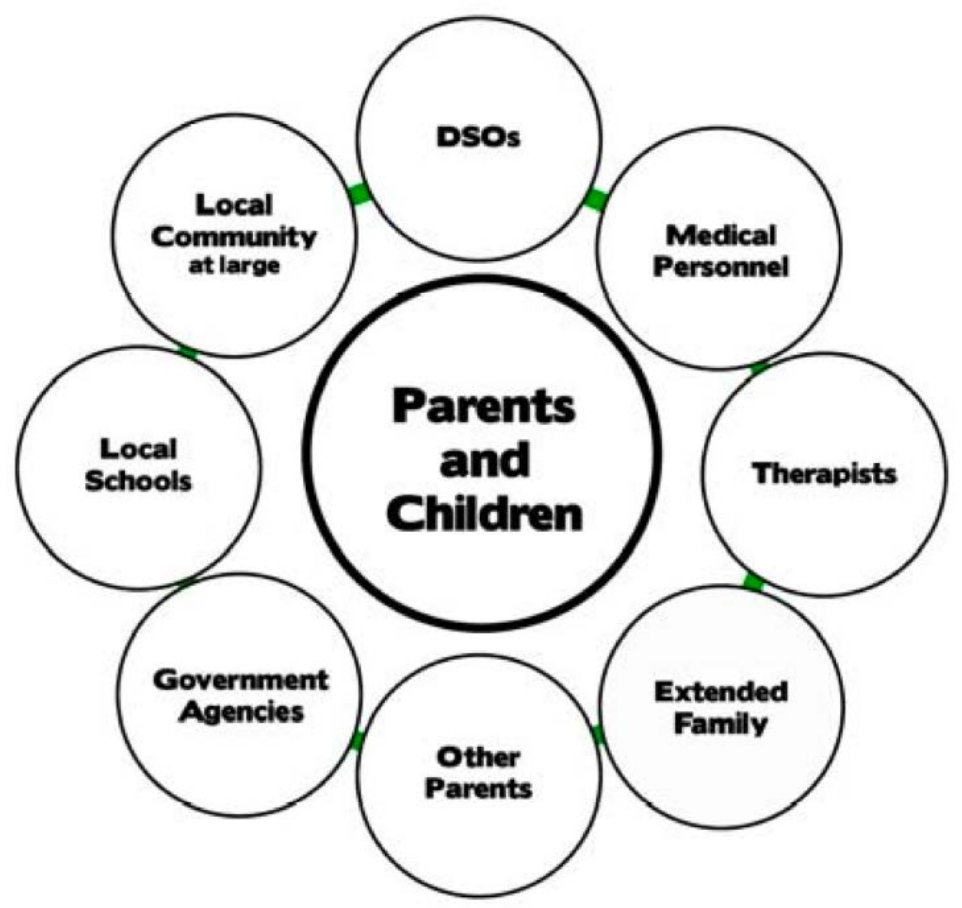

Figure 1: Community Stakeholders

Figure 1 is intended to provide a simple description of stakeholder groups without respect to importance. It does preserve the participants' views with respect to group constituency.

For example, parents viewed therapists as different from other medical personnel, and referred to them as different in interviews, and in information horizons maps. Medical personnel included doctors, nurses, and medical specialists (the most frequently discussed 
were pediatricians, ENTS, pulmonologists, and cardiologists). "DSOs" refers to Down syndrome-related organizations. This group includes local and national organizations.

Parents differentiated between residents of the local community who did not have children with Down syndrome and those who did. For the purposes of this study, parents of children who have Down syndrome are referred to as "other parents." Other residents of the community are referred to as the "Local community at large" (see Figure 1).

The Local Community at Large was most often referred to in terms of affective experiences related to social acceptance and/or rejection, financial and personal support for annual programming (such as the Buddy Walk). Parents did not generally refer to the local community at large as a source of information; instead this actor group was viewed as needing education about Down syndrome.

Government agencies discussed included the Social Security Administration, Medicaid, Medicare, the Agency for Persons with Disabilities, the Department of Education, and the Florida Division of Vocational Rehabilitation. The Early Steps Program, which is a public/private partnership to provide Early Intervention services, was not consistently recognized as a government provided service. Although the majority of the participants' school-aged children attended public school, participants talked about schools as separate from government agencies.

\section{Factors in Community Assessment}

Participants were asked whether they felt they had a strong local community of support. While there was no consensus in either study group as to whether their communities of support were "strong," common themes arose in participants' discussions of what made a strong community of support. Table 1 includes a representative (not exhaustive) list of the categories of factors as coded from interview data. In vivo codes are in italics.

\section{Parents: Individual Parents and the DSO}

Participants frequently cited other parents as the most important resource for information and for referrals to professionals and other information sources, and their relationships to other parents was mentioned frequently as the primary consideration in whether the local community was strong. Three categories of "other parents" appeared in the interview data, represented here as "Other parents," "DSOs" and "Extended family/community at large." The first category, "Other parents" refer to individual parents of other children with Down syndrome. As an example, one participant responded, when asked how she learned about Social Security Disability Insurance (SSDI), "from another child, my child's age's mother."

The second parent category, "DSO" includes organized activity by organizations run by parents of children with Down syndrome locally, or by national affiliates of those organizations. These organizations provided information as well as emotional support. One parent described her first encounter with her local parent organization,

"the night my daughter was born in the hospital...there were two mothers right there to ensure me that there were services, and that I was not some degenerate or drug 
abuser. And they were attractive, intelligent women that gave me the feeling that...other people do this."

\begin{tabular}{|c|c|}
\hline Factors/categories & Open/In vivo codes \\
\hline Other Parents & $\begin{array}{c}\text { parent organization, DSAT, Gold Coast, } \\
\text { lots of programs, Buddy Walk, another } \\
\text { mother }\end{array}$ \\
\hline Community at Large & $\begin{array}{l}\text { acceptance by peers, social outlets in } \\
\text { the general community }\end{array}$ \\
\hline Employment & Goodwill, Publix, voc rehab \\
\hline School system & $\begin{array}{l}\text { inclusion, student/parent rights info, } \\
\text { Least Restrictive Environment }\end{array}$ \\
\hline Transportation & $\begin{array}{l}\text { PalmTran, driving lessons, school bus, } \\
\text { independence }\end{array}$ \\
\hline $\begin{array}{l}\text { Medical/Therapy } \\
\text { services }\end{array}$ & $\begin{array}{l}\text { good doctors, university doctors, current } \\
\text { medical information }\end{array}$ \\
\hline
\end{tabular}

\section{Table 1: Factors in Community Assessment coding examples}

As representatives of the parent organization, the two women mentioned had access to the participant as a new mother, and were able to provide information about local services, basic information about Down syndrome, and emotional support at a critical time. This cooperation between the hospital and the parent organization positively influenced her perception of her local community. Participants generally expressed informal ownership over these organizations, referring to them using terms such as "us" and "ours" and "national parent organizations." It was clear that they viewed these organizations as extensions of the local parent run DSO, and the local parent run DSO as a formalized body of otherwise informally affiliated parents.

The perceived usefulness and level of activity of the parent organization was cited by many participants as the first indicator of the strength of the community of support, even in many cases when the participant did not place emphasis on the organization as their own primary source of information. Support of the National Buddy Walk, an annual fundraising walk organized by local parent organizations and supported by local communities across the United States (National Down Syndrome Society, 2012), was mentioned as indicator of the level of organization of local parents and the support (financial and social/emotional) of the community at large.

Parent interactions differed in the two study groups. The Leon county group placed more emphasis on interaction between individual parents, while the Palm Beach county group described a higher number of interactions directly with the local parent organization. For example, many Leon county participants advised that new parents befriend at least one other local parent of a child with Down syndrome a year or two older than their own child so that they would have a resource for maneuvering through healthcare and educational systems. Parents generally received referrals for services and information sources directly 
from other parents of children with Down syndrome. In Palm Beach County, parents primarily advised that new parents join the local parent organization, and named the organization as the primary source of information related to Down syndrome.

\section{Community at Large and Employment}

Willingness of members in the community at large to voluntarily include individuals with Down syndrome was a common theme in discussion about community strength. Inclusion in recreational activities and participation in the workforce were very important for parents of teenagers and young adults. When asked whether she believed she had a strong community of support, one participant responded,

"Yes. Because of Publix, because of Gold Coast [Down syndrome organization], because of Special Olympics, because of any other...my son has always been in county camp...he's always been able to go to camp with all the other kids. They always went to their public school."

Participants who were parents of young adults (and some teenagers) mentioned vocational training with Goodwill Academy and the Florida Division of Vocational Rehabilitation as important. The willingness of local businesses and schools (as with Publix supermarkets in the example above) to employ people with Down syndrome was also important to these parents, and was mentioned as an indicator of the willingness of the Community at Large to accept and engage with people with Down syndrome.

\section{Schools}

Participants assessments also varied based on whether schools were willing to provide access to a free appropriate public education (FAPE) as guaranteed by Section 504 of Rehabilitation Act of 1973 and the Individual with Disabilities Act (2004) to their satisfaction. Participants cited their ability to access information about their and their child's rights within the school system, teaching and learning, and test taking as indicators of the strength of the local community. Willingness of the local schools system to meet children's needs, and to default to educational inclusion (educating children with peers who have no disabilities in a regular classroom, as opposed to removing them for separate special education services), in keeping with federal law, was very important to parents. One parent who did not agree that her community of support was strong, discussed attempting to enroll her daughter into a "typical" elementary school classroom:

"At the very end of the conversation, it's like 'honestly, because of the classroom size there's not a spot for her...so she needs to go into the full time ESE [exceptional student education] program.' I was absolutely -- I couldn't believe it. I was devastated, and then I didn't know where to go...So...in the education, I still think we have a ton, a ton, a ton, a ton of need for information. That was a very frustrating experience for me. And I wish I did have more information."

Concerns about getting complete information about standardized testing, students' and parents' rights, and funding for students with special needs was a theme for parents of school aged children. The frustration expressed at this lack of information was shared 
between both groups, sometimes with serious educational consequences. One participant discussed finding out that her daughter would have to repeat a grade,

"I said 'I just found out___ was on the list to be retained. She said "yeah, because, if she gets a 1 in reading, because she has never been retained until now, by law she is retained in the third grade.' I said, 'Well, why was I not told that??' She said, 'we didn't tell you?" I said, 'two years ago, we all sat down and all the professors and everybody said 'Yes, yes take the FCAT.' Did somebody mention to me that if she takes it she takes the risk of being retained?' She said, 'I'm looking at the notes. Oh my God, we didn't."

Participants described frustration at these types of situations where information was forgotten or withheld, resulting in negative consequences for children. Participants described feeling insecurity, a "feeling that you don't know what you don't know" that made trust between themselves and their children's schools more difficult to develop. Even when omissions were not seen as intentional, these types of interactions made many participants hyper vigilant about school-related information.

\section{Medical/Therapy Services}

Although the parent group was most trusted in terms of advice and referrals, medical professionals made up the largest quantity of actors in the community of support. Trust in local medical professionals, and the currency of local professionals' information about Down syndrome was also important to participants. There was a perception that local doctors who were unaffiliated with university hospitals did not keep current with rapidly advancing medical developments related to Down syndrome, and changing expectations for children's medical standards. For parents this represented a danger to children's development and, sometimes, survival. One parent discussed her interaction with local professionals,

"I don't have a strong comfort level with the medical community...I just haven't gotten great advice. And then they often have missed information and outdated information, so I would just find, I would tell a family you get your information from the national down syndrome associations your local associations and you find out who in the medical community they recommend and have a good track record. Because the majority do not."

The attitudes of medical professionals also played a large part in participants' assessment of their local communities of support. Another parent wrote about an experience with her child's first pediatrician:

"I think that sometimes there wasn't enough information given because they didn't feel like their quality of life was as important. I had a doctor tell me one time that it might be better if he did not make it through the heart surgery."

In both communities, proximity to university hospitals specializing in health related issues common to children with Down syndrome in the local community was seen as an indicator of community strength. Some parents traveled to access university hospital services, and close proximity to university hospital services was seen as positive because of the services and 
information provided, but also because of the perceived effect of the university hospital on the community at large in terms of education and outreach. Although most participants described good experiences with their own local pediatricians, participants in both communities indicated that a larger number of options for well-trained specialist care (who were trained in updated life expectations and standards for care for children with Down syndrome) was considered desirable.

Parents considered preferred language usage by doctors and other actors within the community at large to be an indicator of their level of knowledge about Down syndrome. Professionals who used people-first language (in which the correct phraseology is "people with Down syndrome" or "child with Down syndrome" as opposed to "Down syndrome boy" or "Down syndrome girl") were considered more trustworthy than those who did not. Any variation of the term "retardation" was viewed as offensive. Parents used the prevalence of these terms, and what they considered to be outdated attitudes about Down syndrome to also evaluate other subsections of their local communities. It is important to note that preferred language might vary between parents of people with Down syndrome and other groups of parents of children with other disabilities within the same local community, and preferred language might vary among parents of children with Down syndrome in different communities. This study does not address these issues, but data made suggests that preferred language usage was important to parents. Further exploration of role of language as a boundary object between information worlds, would help further define its role in building trust within information networks.

\section{Transportation and Distance}

Participants who were parents of teenagers and adults were more likely to consider distance to events and programming, and availability of transportation when assessing their communities. Public transportation was discussed more frequently in the Palm Beach group, with parents equating use of public transportation with independence and employability. Parents of younger children had mixed perceptions of school buses. One parent, describing conflicts between going her returning to the workforce, and transporting her child to therapy services, said,

"I would have to be teaching by 7:30. Then he goes to a different school to get speech therapy for 2.5 hours from 8 to 10:30. Then somebody would have to go back and pick him up, because I would never stick him on a school bus, with all the stuff that's going on...he doesn't even speak."

This is contrasted by other parents who made a point of encouraging independence on the school bus as early as kindergarten.

\section{Comparison and Assessment}

In some cases, participant assessment of the local community was influenced by comparisons with previous communities of residence. In several incidences, these comparisons resulted in action (to add or improve local information/services) by individual parents or by the parent organization, and the availability of information and services were changed for the community as a whole. This finding is consistent with previous studies that 
demonstrated regional variations in medical practices, and the effect of diversity in medical residents in hospital departments (Wennberg, 2002). The larger urban community demonstrated more instances of this comparative assessment.

\section{Importance of Anchor Institutions}

Because Down syndrome has the potential to affect a number of different areas of an individual's life, parent/caretakers must often familiarize themselves with a range of conditions, related language, organizations and regulatory systems. Most of the participants' children regularly consulted with 3 or more therapists (speech, physical and occupational therapy), a pediatrician, and 2-3 specialists (at least for annual checks as per the AAP guidelines for individuals with Down syndrome)(American Academy of Pediatrics, 2011). Additionally, participants coordinated special education services (IEP/Individualized Education Planning) with local school systems. Some participants' children were Medicaid recipients, received Social security benefits, and other services. Because each child had different needs, each parent found him/herself at the nexus of a unique set of information worlds (Jaeger \& Burnett, 2010). Government and not-for-profit agencies that work with individuals with Down syndrome often work with individuals with a wide range of conditions, and are not equipped to focus in great detail on the specific needs of people with Down syndrome and their families. Parents described sometimes feeling overwhelmed.

The parent-run organization served as an anchor and central repository of information in the local community for these parents, who shared similar experiences, but each of whom had slightly different needs. The parent organization served to build a sense of community and sense of place for parents who described themselves as not regularly active in the organization. While these parents referred to themselves "outsiders," they acknowledged the role of the parent organization as central to the community. Similar studies of health-related community organization have focused on churches (Abanilla et al., 2011; Kaziunas, Ackerman, \& Veinot, 2013). For organizations, understanding the factors local community members use in evaluating the community of support could provide a starting point for community outreach and programming. For organizations that want to share information with parents, understanding the role of the organization in the local community could help in planning outreach.

\section{Trust and Expertise in Professional Settings}

As with other types of groups, participants considered other parents of children with Down syndrome to be cognitive authorities (Rieh, 2005), and sought peers as primary information sources before others (including medical professionals). They also used the parent network as a formal and informal referral mechanism for seeking medical, therapy and educational expertise. This network meditated legitimation (Haythornthwaite, 1996; Veinot, 2009), mirrors network interactions among individuals with HIV in Canada (Veinot, 2009). The parents sharing experiences are engaging in behavior that reduces the level of information poverty in their information world and local community, and may ultimately improve outcomes for their children (Feinber, Willler, \& Keltner, 2012).

The following were factors mentioned as determinants of trust in medical professionals: 
Language - Participants expected medical professionals to use people first language. Use of terms that were perceived as dated (such as "Downs kids" or "mental retardation") suggested to parents that the professional also had dated attitudes and did not have access to or use current information. For these parents, language provided a quick litmus test of professional competency.

Understanding of the role of the parent network. Participants valued the parent network important as important for referrals and legitimation. Situations in which professionals were hostile toward the concept of information sharing between parents were described negatively.

Accuracy and currency of information. Participants described situations in which medical and educational professionals were found to use information or hold attitudes toward individuals with Down syndrome that was not current or inaccurate negatively. Participants who had these experiences were likely to evaluate information based on sources provided by local or national Down syndrome advocacy organizations. They were also likely to seek further care or education elsewhere.

Trust was closely guarded in both study communities, as parents are protective of their children. Here again, language was used to indicate belonging in the community and to isolate outsiders. A dichotomy of opposition is discernable in the parents' use of the term "our kids" to describe children with Down syndrome. Parents often used the term as shorthand (instead of saying "children with Down syndrome") as a boundary between themselves and outsiders.

\section{Conclusions}

This paper explores factors related to community evaluation of information access, seeking and sharing in two communities of parents of children with Down syndrome in Florida. This study does not seek to provide generalizable results. Instead it considers important variations between communities useful for localizing health information and services (Kaziunas, Ackerman, \& Veinot, 2013). It also uses grounded theory to frame community issues in the language of the parents, rather than that of the researcher. Future research will further explore information worlds of parents of children with Down syndrome, focusing on emergent information worlds and information behavior.

When discussing their evaluations of their local communities, parents assessed experiences with one or more of the following eight stakeholder groups: DSOs (Down syndrome-related organizations), Medical Professionals, Therapists, Extended family, Other parents of children with Down syndrome, Community at Large, Local schools, and Government agencies.

Participants uniformly expressed the general belief that some communities were "better" than others, but were not uniform in their evaluation of their own communities. Individual perceptions of what traits were most important varied based on parents' and children's needs, but parents cited the one or more of the following factors when considering whether their area had a strong community of support for families of people with Down syndrome:

- Parent organization

- Medical 
- Transportation/Proximity to services local information

- Social interaction and acceptance in the Community at large

- Schools/Access to appropriate education

Participants' examples, or justifications of their assessments of their communities of support fell into one of three categories: descriptions of information or services provided by local stakeholders (information and services), assessment of facilities and accessibility of spaces and information (distance and travel), and social/affective descriptions of social interactions (acceptance and inclusion).

Participants viewed information as necessary managing their children's health and wellbeing, and many explicitly discussed the importance and difficulty of managing information between themselves, their children, and other actors that make up their information worlds. They perceived access to information as a right, and necessary to ensure positive health outcomes for their children May of the participants viewed the parent organization and the informal parent network as anchors to the local community, seeking, verifying and distributing information. Because of this, they were the most important factor in most participants' evaluations of their local communities. Further research is needed to explore how these anchor institutions improve health-related and other types of information literacy, and the extent to which they improve outcomes for people with Down syndrome and their families.

\section{Acknowledgments}

The researcher would like to thank the participants and parent support organizations for sharing their experiences. Thanks also to Michelle Kazmer for her guidance in the undertaking of this research, and to Barbara Wildemuth and anonymous reviewers for their constructive comments on this article.

\section{References}

Ammari, Tawfiq, Meredith Ringel Morris, and Sarita Yardi Schoenebeck. 2014. "Accessing Social Support and Overcoming Judgment on Social Media among Parents of Children with Special Needs." In Proceedings of the 8th International Conference on Weblogs and Social Media, ICWSM 2014, 22-31.

Abanilla, Patricia Karen A., Keng-Yen Huang, Daniel Shinners, Andrea Levy, Kojo Ayernor, Ama de-Graft Aikins, and Olugbenga Ogedegbe. 2011. Cardiovascular disease prevention in Ghana: Feasibility of a faith-based organizational approach. Bulletin of the World Health Organization 89 (9): 648-56.

American Academy of Pediatrics. 2011. Clinical report - Health supervision for children with Down syndrome. Retrieved from http://ndsccenter.org/worpsite/wpcontent/uploads/2012/04/AAP-Guidelines.pdf

Agnew, John A. 1987. The United States in the World-Economy: A Regional Geography. Cambridge; New York: Cambridge University Press.

Atkinson, Leslie, Brian Scott, Vivienne Chisholm, Janis Blackwell, Susan Dickens, Francis Tam, and Susan Goldberg. 1995. Cognitive coping, affective distress, and maternal sensitivity: Mothers of children with Down syndrome. Developmental Psychology 31 (4): 668-76. 
Bittles, Alan. H., \& Glasson, E. J. 2004. Clinical, social, and ethical implications of changing life expectancy in Down syndrome. Developmental Medicine and Child Neurology 46 (4): 282-6.

Bittles, Alan H., Carol Bower, Rafat Hussain, and Emma J. Glasson. 2007. The four ages of Down syndrome. European Journal of Public Health 17 (2): 221-5.

Day, Graham. 2006. Community and Everyday Life. 1 edition. London; New York: Routledge.

Dobransky, Kerry, and Eszter Hargittai. 2006. The disability divide in internet access and use. Information, Communication \& Society 9 (3): 313-34.

Fitzgerald, Patrick, Helen Leonard, Terri J. Pikora, Jenny Bourke, and Geoffrey Hammond. 2013. Hospital admissions in children with Down syndrome: Experience of a populationbased cohort followed from birth. Plos One 8 (8): e70401.

Feinberg, Matthew, Robb Willer, Jennifer Stellar, and Dacher Keltner. 2012. The virtues of gossip: Reputational information sharing as prosocial behavior. Journal of Personality and Social Psychology 102 (5): 1015-30.

Gastaldo, Denise, Gavin J. Andrews, and Nazilla Khanlou. 2004. Therapeutic landscapes of the mind: Theorizing some intersections between health geography, health promotion and immigration studies. Critical Public Health 14 (2): 157-76.

Grekousis, George, and Yorgos N. Photis. 2014. Analyzing high-risk emergency areas with GIS and neural networks: The case of Athens, Greece. Professional Geographer 66 (1): 124-37.

Haythornthwaite, Caroline. 1996. Social network analysis: An approach and technique for the study of information exchange. Library and Information Science Research 18 (4): 32342.

Herb, Guntram Henrik, and David H Kaplan. 1999. Nested Identities: Nationalism, Territory, and Scale. Lanham, Md.: Rowman \& Littlefield Publishers.

Hill, Heather. 2013. Disability and accessibility in the library and information science literature: A content analysis. Library and Information Science Research 35 (2): 137-42.

Huang, C. J. 2003. "Usability of E-Government Web-Sites for People with Disabilities." In 36th Annual Hawaii International Conference on System Sciences, 2003. Proceedings of The, 11 pp. https://doi.org/10.1109/HICSS.2003.1174330.

Jegatheesan, Brinda, Susan Fowler, and Peggy J. Miller. 2010. From symptom recognition to services: How south asian muslim immigrant families navigate autism. Disability and Society 25 (7): 797-811.

Jaeger, Paul T. 2006. Assessing section 508 compliance on federal e-government web sites: A multi-method, user-centered evaluation of accessibility for persons with disabilities. Government Information Quarterly 23 (2): 169-90.

Jaeger, Paul T, and Gary Burnett. 2010. Information Worlds: Social Context, Technology, and Information Behavior in the Age of the Internet. New York: Routledge.

Kaziunas, Elizabeth, Mark S. Ackerman, and Tiffany C. E. Veinot. 2013. Localizing chronic disease management: Information work and health translations. Proceedings of the American Society for Information Science and Technology 50 (1): 1-10.

Pacione, Michael. 1983. Progress in Rural Geography. London: Barnes \& Noble Books.

Mackintosh, Virginia. H., Barbara J. Myers and Robin P. Goin-Kochel. 2005. Sources of information and support used by parents of children with autism spectrum disorders. Journal on Developmental Disabilities, 12(1), 41-51. 
Mai, Cara T., James E. Kucik, Jennifer Isenburg, Marcia L. Feldkamp, Lisa K. Marengo, Erin M. Bugenske, Phoebe G. Thorpe, et al. 2013. Selected birth defects data from population-based birth defects surveillance programs in the United States, 2006 to 2010: Featuring trisomy conditions. Birth Defects Research Part A: Clinical and Molecular Teratology 97 (11): 709-25.

National Down syndrome Society. 2012. Buddy walk. Retrieved from http://www.ndss.org/Buddy-Walk/

Paasi, A. 2012. Commentary Border studies reanimated: going beyond the territorial/relational divide. Environment and Planning A, 44(10), 2303 - 2309. doi:10.1068/a45282

Pain, H. 1999. Coping with a child with disabilities from the parents' perspective: The function of information. Child: Care, Health and Development 25 (4): 299-313.

Parker, Samantha E., Cara T. Mai, Mark A. Canfield, Russel Rickard, Ying Wang, Robert E. Meyer, Patrick Anderson, et al. 2010. Updated national birth prevalence estimates for selected birth defects in the United States, 2004-2006. Birth Defects Research Part A Clinical and Molecular Teratology 88 (12): 1008-16.

Rais, Abdur, and Ana Vianaa. 2011. Operations research in healthcare: A survey. International Transactions in Operational Research 18 (1): 1-31.

Rieh, S. Y. 2005. "Cognitive authority." In Theories of Information Behavior, edited by Karen E. Fisher, Sanda Erdelez, and Lynne (E.F.) McKechnie, 83-87. Medford, NJ: Information Today.

Rodrigue, J. R., S. B. Morgan, and G. R. Geffken. 1992. "Psychosocial Adaptation of Fathers of Children with Autism, Down Syndrome, and Normal Development." Journal of Autism and Developmental Disorders 22 (2): 249-63.

Shin, Mikyong, Lilah M. Besser, James E. Kucik, Chengxing Lu, Csaba Siffel, Adolfo Correa, Congenital Anomaly Multistate Prevalence and Survival (CAMPS) Collaborative, Congenital Anomaly Multistate Prev, Congenital Anomaly Multistate Prevalence and Survival Collaborative, and the Congenital Anomaly Multistate Prevalence and Survival (CAMPS) Collaborative. 2009. Prevalence of Down syndrome among children and adolescents in 10 regions of the united states. Pediatrics 124 (6): 1565-71.

Sonnenwald, Diane H., Barbara M. Wildemuth, and Gary L. Harmon. 2001. "A Research Method to Investigate Information Seeking Using the Concept of Information Horizons: An Example from a Study of Lower Socio-Economic Students' Information Seeking Behaviour." New Rev. Inf. Behav. Res. 2 (November): 65-86.

Veinot, Tiffany C. 2009. Interactive acquisition and sharing: Understanding the dynamics of HIVIAIDS information networks. Journal of the American Society for Information Science and Technology 60 (11): 2313-32.

Veinot, Tiffany C., and Roma Harris. 2011. Talking about, knowing about HIVIAIDS in Canada: A rural-urban comparison: Talking about, knowing about HIVIAIDS in Canada. The Journal of Rural Health 27 (3): 310-8.

Veinot, Tiffany C., and Kate Williams. 2012. Following the "community" thread from sociology to information behavior and informatics: Uncovering theoretical continuities and research opportunities. Journal of the American Society for Information Science and Technology 63 (5): 847-64.

Veinot, TC, CC Meadowbrooke, J. Loveluck, A. Hickok, and JA Bauermeister. 2013. How "community" matters for how people interact with information: Mixed methods study of young men who have sex with other men. Journal of Medical Internet Research 15 (2): 180-200. 
Wennberg, John E. 2002. Unwarranted variations in healthcare delivery: Implications for academic medical centres. Bmj 325 (7370): 961-4.

Yang, Quanhe, Sonja A. Rasmussen, and JM Friedman. 2002. Mortality associated with Down's syndrome in the USA from 1983 to 1997: A population-based study. The Lancet 359 (9311): 1019-25. 